Article

\title{
Organising for Co-Production: Local Interaction Platforms for Urban Sustainability
}

\author{
Beth Perry ${ }^{1, *}$, Zarina Patel ${ }^{2}$, Ylva Norén Bretzer ${ }^{3}$ and Merritt Polk ${ }^{4}$ \\ ${ }^{1}$ Urban Institute and Urban Studies and Planning, University of Sheffield, Sheffield, S10 2TN, UK; \\ E-Mail: b.perry@sheffield.ac.uk \\ 2 Department of Environmental and Geographical Sciences, University of Cape Town, Cape Town, 7700, South Africa; \\ E-Mail: zarina.patel@uct.ac.za \\ 3 Department of Public Administration, University of Gothenburg, 40530 Gothenburg, Sweden; \\ E-Mail: ylva.noren-bretzer@spa.gu.se \\ ${ }^{4}$ School of Global Studies, University of Gothenburg, 40530 Gothenburg, Sweden; E-mail: merritt.polk@globalstudies.gu.se \\ * Corresponding author
}

Submitted: 14 October 2017 | Accepted: 22 January 2018 | Published: 3 April 2018

\begin{abstract}
Urban sustainability is a wicked issue unsuited to management through traditional decision-making structures. Co-productive arrangements, spaces and processes are inscribed in new organisational forms to bridge between diverse forms of knowledge and expertise. This article suggests that local interaction platforms (LIPs) are innovative responses to these challenges, developed in two African and two European cities between 2010 and 2014 . Through elaborating the design and practice of the LIPs, the article concludes that the value of this approach lies in its context-sensitivity and iterative flexibility to articulate between internationally shared challenges and distinctive local practices. Six necessary conditions for the evolution of LIPs are presented: anchorage, co-constitution, context-sensitivity, alignment, connection and shared functions. In the context of increased uncertainty, complexity and the demand for transdisciplinary knowledge production, the platform concept has wider relevance in surfacing the challenges and possibilities for more adaptive urban governance.
\end{abstract}

\section{Keywords}

boundary spaces; co-production; collaborative governance; hybridization; local interaction platforms; Mistra Urban Futures; transdisciplinarity; urban experimentation; urban sustainability

\section{Issue}

This article is part of the issue "Co-Producing Urban Governance for Social Innovation, edited by Liz Richardson (University of Manchester, UK).

(C) 2018 by the authors; licensee Cogitatio (Lisbon, Portugal). This article is licensed under a Creative Commons Attribution 4.0 International License (CC BY).

\section{Introduction}

The Zero Draft of the New Urban Agenda for Habitat III notes how population growth poses massive systemic challenges: "the battle for sustainable urban development will be won or lost in cities...there is a need for a radical paradigm shift in the way cities and human settlements are planned, developed, governed and managed" (United Nations Habitat III Conference, 2016, p. 1). Urban sustainability is a wicked issue, requiring the knowl- edge and skills of multiple disciplines, sectors and stakeholders. This perspective is rooted in the idea of coproduction and is symptomatic of the wider contextualisation of science and need to value and incorporate knowledge production processes beyond the academy (Durose \& Richardson, 2015; May \& Perry, 2017a). Developing strategic solutions to urban sustainability problems is a "quintessential epistemic mess" (Bulkeley \& Betsill, 2005) which urban coalitions need to manage, where causes and consequences are embedded within multi- 
ple layers of urban society. Addressing urban sustainability problems requires capacity to integrate and manage a huge range of intersecting forms of global and local knowledge to develop appropriate policy responses, instruments and interventions (Moser, 2013).

As traditional siloed organisations are unable to solve their internal conflicting goals, coordinating mechanisms are needed (Head \& Alford, 2015). Dealing with wicked issues and strategic messes at the urban level has encouraged experimentalism to address this challenge (May \& Perry, 2016a). Numerous initiatives have sprung up in different contexts with the common goal of creating "third" or "boundary spaces" requiring collaborative governance arrangements (Ansell \& Gash, 2007). Practice is leading theory, meaning that such boundary experiments become rich sites for inductive learning. There remain gaps in the literature about the value of different organisational responses to foster transdisciplinary learning through cross-boundary working, the conditions which support or hinder innovative mechanisms and the wider challenges and implications for urban governance.

This article contributes to understanding organisational mechanisms, issues and conditions shaping responses to complex urban sustainability challenges. It does so through an inductive analysis of local interaction platforms (LIPs), as a new mode of organising knowledge and expertise beyond the academy. LIPs are an innovation of the Mistra Urban Futures centre, a sustainability research and practice centre headquartered in Gothenburg, Sweden. The core mission of the Centre is to generate and use knowledge to support transitions towards sustainable urban futures through transdisciplinary co-production at local and global levels. The primary organisational mechanism for delivering the vision and mission was to set up an international network of LIPs to bridge between different stakeholders and recombine diverse forms of expertise to address urban challenges. LIPs were established in Gothenburg (Sweden), Greater Manchester (UK), Kisumu (Kenya) and Cape Town (South Africa).

Through drawing on the design and practice of these LIPs between 2010 and 2014, the research reveals a central challenge in organisational responses to urban sustainability: the need for flexibility to respond to diverse and changing urban contexts and to broker between global and local forms of knowledge. Our work suggests that LIPs are innovative responses to this challenge, allowing for context-sensitivity and iterative flexibility to articulate between internationally shared priorities and distinctive local practices. LIPs have evolved thanks to similar necessary conditions at each platform: anchorage, co-constitution, context-sensitivity, alignment, connection and shared functions. This commonality across African and European city-regions points to the wider relevance of the "platform" concept for urban decisionmaking in the context of increased uncertainty and complexity and the demand for transdisciplinary knowledge production (May \& Perry, 2017b).

\section{From Wickedness to Experimentalism and Institutional Innovation}

The term "wicked" issue was coined by Rittel and Webber back in 1973, as they concluded that contemporary intelligence was insufficient to the complex task of planning across multiple domains, given the pluralities of interests and objectives involved. Whilst science is about "taming", planning problems are getting wilder and more "wicked" (1973, p. 160). The rise of such issues is associated with the contextualisation of science in society and the wider advent of the "risk society" (Beck, 1992). Conditions of risk, uncertainty and complexity have led others to talk about "messes", a term used to characterise systems of problems which need to be addressed (Ackoff, 1979, pp. 90-100). Complex problems have little consensus on how to solve them and often take place in contested and negotiated policy arenas. There are also irreconcilable tensions in how to respond to economic, social and ecological grand challenges, which have not been mediated or resolved by international or national governments, and are passed to cities and local governments to manage.

The complexity of urban issues, in which cities are both sites and solutions to intractable global challenges, means that both "wickedness" and "messiness" characterise the current urban moment, leading to demands for different forms of expertise and knowledge (Polk, 2015). These forms of expertise lie across disciplines, sectors, institutions and communities, giving rise to an emphasis not only on inter- but also transdisciplinarity (Lang et al., 2012). Transdisciplinary knowledge production requires co-productive processes, which take seriously the question of integrating different sources of knowledge and expertise. Co-productive "boundary spaces" are said to enable the knowledge and expertise of different participants to be recognised based on respect, openness and deliberation, requiring that "contributions from specific disciplines and social actors are not privileged over what other disciplines and social actors contribute" (Pohl et al., 2010, p. 217).

We have witnessed the rapid growth of different organisational forms and co-productive partnership arrangements at the urban level, many of which include universities as strategic partners. Against the backdrop of the "partnership paradigm" (Glasbergen, Biermann, \& Mol, 2007, p. 3), university-city partnerships have been developed in multiple contexts and in different forms (Trencher, Bai, Evans, McCormick, \& Yarime, 2014). Whilst diverse in their function, scale and scope, there are three common trends. The first is the shift to more collaborative governance where multiple stakeholders come together in common forums to engage in consensus-oriented decision-making (Ansell \& Gash, 2007 , p. 543). Classical problems of the commons are solved, according to such theories, through collaborative institutional arrangements as complementary structures dealing with improved sustainability in the urban 
field (Ostrom, 1990). The second is an emphasis on experimentation. There is a plurality of urban experiments, which have been variably interpreted. Experimental initiatives can be ways of managing risk and dealing with uncertainty (Evans, 2016; May \& Perry, 2016a). With limited resources and time, the experiment acts as a pilot prior to rolling out approaches or solutions across different sites (Bulkeley \& Castán Broto, 2013). The third trend in university-city partnerships is a reassertion of the importance of spatial context as a testbed for new technical and social innovations (May \& Perry, 2017b). This relates to a rejection of the idea of best practice models transplanted around the world without sensitivity to context (Patel, Greyling, Parnell, \& Pirie, 2015).

Collaborative governance, experimentation and context-sensitivity are essential preconditions in the search for solutions to complex epistemic messes and wicked urban problems (Ansell \& Gash, 2007). Collaborative partnerships are characterized by multiple partners exercising power in the decision-making process, pooling resources, operating under a consensual decision frame and harmonising activities (Kernaghan, 1993, p. 62). There is a need for new types of learning that can promote social and technical innovation, through the systemic search for new and effective processes, methods and tools for multi-level and multi-stakeholder governance (Pelling, High, Dearing, \& Smith, 2008). Whilst within technical and post-austerity discourses we see the drive for innovations that can be "rolled out to the market", sustainability discussions emphasise transition, requiring institutional reconfiguration and different kinds of social and sustainable innovations (Grin, Rotmans, \& Schot, 2010; Voß \& Bornemann, 2011).

Theory is catching up with practice. Three key questions remain underexplored in the literature: how do different initiatives respond to the need for collaborative governance, experimentation and context-sensitivity? What are the common conditions across different contexts, which shape organisational responses? What can we learn from new organisational responses about the issues and challenges in co-producing knowledge for sustainability? We respond to these research questions through an inductive analysis of the design and practice of LIPs.

\section{Methodology}

Mistra Urban Futures is a Centre with headquarters in Gothenburg created in response to the need for new organizational forms that could blend knowledge and expertise within and across urban contexts (Polk, Malbert, \& Kain, 2009). It was founded on the premise that bridging knowledge gaps entails boundary breaking, alongside the need to develop the capacity to learn systematically from different localized development processes in a comparative framework. Four pillars underpinning knowledge production in the Centre were defined (Figure 1).

LIPs were formed in Gothenburg ("GOLIP" in Sweden), Greater Manchester ("GMLIP" in UK), Kisumu ("KLIP" in Kenya) and Cape Town ("CTLIP" in South Africa). The selection of city contexts was based on the criteria of secondary, intermediate cities in different contexts, with pre-existing histories of collaborative working with Gothenburg. The local partners in Gothenburg had a strong track record of cooperation drawing on the post-industrial traditions of the harbour city, being home to large industry firms such as Volvo, Ericsson, SKF and AstraZeneca (Polk, 2015). The Greater Manchester platform was anchored in the Centre for Sustainable Urban and Regional Futures (SURF) at the University of Salford Manchester, which had also contributed to Mistra's pre-call evidence gathering process (Mistra, 2008). SURF had a record of working locally with policy-makers, businesses and community groups, through critical engagement with knowledge-based urban development initiatives. This had led to bilateral links between SURF and the GOLIP consortium in the years prior to the submission. In Kisumu, the establishment of the LIP built upon pre-existing relationships between Chalmers University in Gothenburg and East Africa, and the prior work of the Kisumu Action Team (KAT), initiated by the Mayor of Kisumu and comprising local informal stakeholder organisations, such as residents, public and private sectors, civil society and academia. The African Centre for Cities

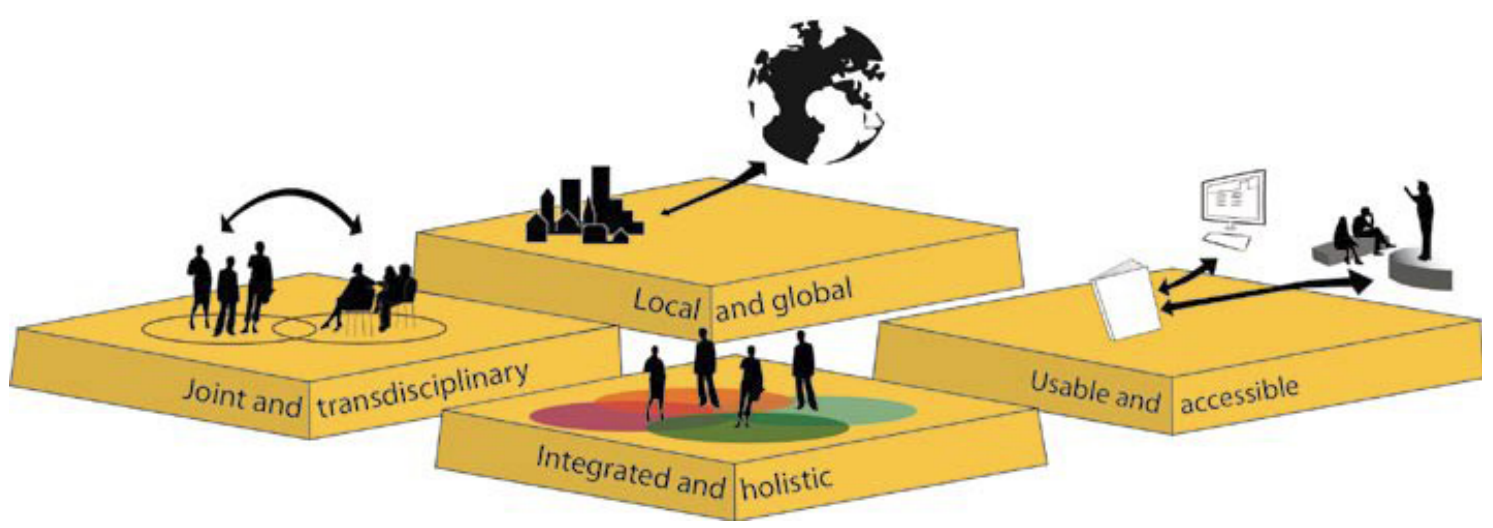

Figure 1. Principles of knowledge production. Source: Kain, Nolmark, Polk and Reuterswärd (2011, p. 18). 
(ACC) at the University of Cape Town (UCT) had originally been part of a competing submission, but was asked by the co-funder, the Swedish International Development Agency (SIDA), to join the Gothenburg consortium and anchor Mistra Urban Futures in the Global South along with Kisumu.

This article presents an inductive, comparative analysis of experiences across the LIPs in organising to address wicked urban sustainability challenges. It draws on secondary analysis of process documentation, group writing and interview exercises. The research is inductive in the sense that we analyse the design and practice of the four platforms (two in Africa and two in Europe) as cases to reveal broader conditions and challenges. This is assisted through each LIP having similar setting conditions and characteristics, given they have developed within a common framework. The initial call for a transdisciplinary centre in urban sustainability by the Mistra Foundation stipulated common criteria for partners: matched funds and public-university partnerships. Each LIP developed under the same guidelines and according to the same principles, but adapted and implemented these in different ways. Local and comparative projects were undertaken and analysed in their own right; at the same time a process of meta-learning and comparison to analyse lessons emerging from practice. Each LIP undertook its own process of formative evaluation internally through workshops and interviews, followed by commissioned independent evaluations at the local level. An independent international advisory group undertook a Centre-wide progress review in 2014-2015 (Mistra Urban Futures, 2015). Following this, the Directors of the LIPs undertook a collaborative writing exercise (Palmer \& Walasek, 2016) and group interview (Norén Bretzer, 2016) to support meta-learning comparatively across the platforms.

Whilst the experiences of the LIPs deviate from each other, making strict control of variables difficult, there are advantages to this approach. Parallel processes of local and trans-local reflection enable a wide range of perspectives across different geographic scales and contexts. This aids rich and thick descriptions of cases (Geertz, 1973) as a first step prior to meta-comparative analysis. Internal reflexive learning by participants (May \& Perry, 2017a) is cross-referenced with independent evaluations by experts outside the study field. Knowledge generated locally by researchers, deeply embedded in each urban context, is aligned and tested for comparative credibility and cogency. Whilst we have not deployed a strict comparative method, our approach of "double loop metalearning" is consistent with the topic of the study (Argyris \& Schön, 1974). To this extent, our methodology mirrors the urban world in which the platforms are located in the context of increasing urban complexity and the contextualisation of science in society (Nowotny, Scott, \& Gibbons, 2001). In the remainder of this article, we address our three research questions by setting out the collaborative governance arrangements of the LIPS, competing logics that have shaped the devolution and evolution of the LIP concept and the conditions under which each has developed. We then consider the wider implications of the platform concept for urban governance under conditions of uncertainty and complexity.

\section{Learning by Doing: Inside LIPs}

\subsection{Mechanisms for Collaborative Governance}

Co-governance and co-funding were two key principles for each LIP. This translated, in operational terms, into the need for shared ownership, joint leadership and a mixed economy of funding for each platform. In practice, the LIPs were organised and funded in different ways. Some LIPs formed multi-sectoral consortia, such as in Gothenburg, with coordinators representing their institutions within regular board-style meetings and decisionspaces. Some LIPs anchored more firmly within existing research environments in universities, whilst others sought to distance themselves from specific organisational affiliations. This was also a practical consideration linked to the ability of different institutions to receive, manage and audit funding. For instance, like GOLIP, KLIP involved formal collaboration between two universities (Maseno and Jaramongi Oginga Odinga University of Science and Technology). However, their direct influence was minimised by the creation of an independent Trust. The perception was that: "it would have been very difficult to persuade the partners to come to one of the participating universities for meetings; they would have thought it was a university-driven agenda" (Group Director interview, 2016). Unlike GOLIP and CTLIP, where collaborative governance translated into strong relationships between public institutions, the partnerships in Kisumu and Greater Manchester aimed more explicitly to build greater participation from residents and civil society into their programmes of work.

Co-financing was a condition of receiving funding from the Mistra Urban Futures centre. As the original applicant, the Gothenburg consortium developed during the bidding phase; considerable in-kind and cash resources had already been secured from partners. The consortium was also successful in securing funding from the SIDA. Both arrangements had consequences for the way in which finance could be allocated towards the LIPs. For instance, the Centre had hoped to move to a system of basket funding, but instead had strict rules regarding the use and accounting of different sources of finance. This involved high levels of bureaucracy for each financial stream and shaped the construction of local partnerships.

Two examples illustrate this co-constitution between context, structures and funding mechanisms. First, KLIP and CTLIP were the only legitimate recipients of SIDA funding and subject to regular auditing, reflecting a more traditional donor-client relationship. Receiving split funding from two funders meant meeting different, and sometimes competing, expectations relating to climate 
change adaptation and mitigation and local policy relationships (from the Mistra Foundation) and poverty reduction across Africa (from SIDA). Second, whilst receiving lower levels of cash funding and subject to interim cuts in allocations, GMLIP was able first to align and then attract relatively flexible external UK research council funds to match their involvement in the Centre. This was particularly important in a context of austerity, which had created huge organisational uncertainty, personnel churn in local government and savage budget cuts. Uniquely, in GMLIP an initial transfer of resources secured the engagement of policy officials and other partners to incentivise engagement at a time of rapid flux. A more networked model for the GMLIP developed, compared with the structured relationship between ACC and the City of Cape Town, which formed the central axis for CTLIP.

For GOLIP the situation was complicated. GOLIP was significantly larger than the other LIPs, based on the original intention to have a large central research centre with smaller international platforms for collaboration and networking. However, the distinction between the GOLIP and the Centre itself was initially blurred, both financially and operationally, leading to muddy lines of accountability and strategic direction. A key asset of GOLIP was high levels of in-kind resources, taken to signify buy-in and commitment from partners, as well as the allocation of nodal "coordinators" from each institution. However, this led to tensions in practice undermining the cooperative ethos, as highlighted during the group LIP Directors' interview: "the in-kind is really the main strength of the platform...but when you start transferring money, then it becomes difficult; then you need to have contracts, and it creates relationships that you might not want...hierarchies and structures" (Group Director interview, 2016).

\subsection{Between Local and Global: Logics of Scale}

LIPs developed local projects based on established partnerships, existing priorities and identified needs. In GOLIP, the structures and financing allowed for representation by different partners as equals, with no preferential position for the academic institutions, despite Chalmers' official position as host. This reflected the spirit of the Centre, but also meant a greater risk of competition for funds and increased difficulty of achieving coherence across a large and diverse portfolio. Comparatively, in GMLIP, the funding model reinforced the institutional power of the university and positioned academics as intellectual leads. However, this was not contested by city-regional partners, who experienced the platform in a free and creative way. Given the turbulent environment in which they worked, city partners welcomed the absence of responsibility or commitment for more active management. A smaller number of linked projects were subsequently developed with each partner at the GMLIP, where there was good fit between local issues and the
Centre's research and practice agenda. In Kisumu, the focus was on two large projects around market places and sustainable tourism, delivered by Masters and PhD students to build research capacity for the future. CTLIP aligned with and supported multiple projects and partners, whilst also anchoring the platform in a new Knowledge Transfer Partnership (KTP) with the City of Cape Town. The KTP involved embedding PhD students in local government departments and exchanges with policy officials. As such, the projects at the different LIPs show little similarity. This flexibility and diversity was seen by the LIPs (and eventually by the Centre following the midterm evaluation) as a key strength, enabling them to articulate, reflect and challenge local contexts (Mistra Urban Futures, 2015).

Variations in the co-financing and structuring of the LIPs circumscribed the ability and legitimacy of the Centre to formulate and impose a common programme of work. At the same time, two major comparative projects were developed to respect context-sensitivity and also draw lessons from across international urban contexts. These projects provided a highly valuable role in bringing LIP teams together to work on shared concerns. A common project, Governance and Policy for Sustainability ("GAPS"), was initiated in 2012 to support the development of the Centre (Marvin \& May, 2017). This was "a substantive vehicle" for better understanding the national and city-regional contexts in which more progressive sustainable urban development could be seeded (Marvin \& May, 2017). The purpose of GAPS was to constitute a baseline for comparative learning and to understand issues in different contexts, in order to inform the development of the scientific programme for the Centre. A second pilot project focusing on the implementation of the Urban Sustainable Development Goal ("USDG project") was introduced across the LIPs in 2015. Like GAPS, the USDG project was managed centrally, but implemented locally. In both cases, whilst the broad questions and research template were largely defined by the project leads, implementation, data gathering and reporting was led by local researchers responding to local opportunities and constraints. In representing the work, synthetic articles, special editions and stand-alone articles sought to bring coherence to the analysis with a focus on comparative learning, rather than the imposition of a strict comparative method (see for instance, Davison, Patel, \& Greyling, 2016; Perry \& Atherton, 2017; Simon et al., 2015). The non-prescriptive approach to the mechanisms for LIPs to organize at the local level acknowledged the shortfalls of "best practice" approaches. In comparative work: "what can be replicated are the approach and the philosophy behind it but not the procedures and activities" (Shami, 2003, p. 80).

The result of the evolution of the LIPs has been a rebalancing of structures of power between the Centre, the GOLIP and other partners over time. In this first phase, it was not always clear whether the Centre was based on the roll-out of the GOLIP model across other 
platforms, or whether GOLIP was first-among-equals. Whilst originally assumed to be satellites to Gothenburg and implement their methods, each LIP became equal partners, if not equal financial recipients, in the design and development of the Centre. This outcome reflected resistance to a one-size-fits-all model imposed on the LIPs, given the irrefutable logic of local contextualisation, driven by co-production, co-financing and partnership arrangements. As one LIP Director noted, "it's coproduction out there and command and control in here" (Group Director interview, 2016). This produced tension in the design and organisation of the Centre; early efforts to regulate and control centrally were pushed back by the non-Swedish LIPs, particularly Greater Manchester and Cape Town. This surfaced the evident need to balance local context and power with central control and alignment. As a result, whilst the LIPs operated with high levels of flexibility and adaptability to enable coproductive boundary spaces in each urban context, the balance between global and local favoured the latter. In the end most projects reflected a common orientation towards locally-generated processes and practices for urban sustainability transformations.

\subsection{Six Conditions Shaping Organisational Responses}

As is common in many collaborative partnerships, the LIPs grew from existing and established relationships in each of the four cities (Ansell \& Gash, 2007, p. 550). In all cases, "the soil was fertile and had been cultivated for some substantial years before the Mistra Urban Futures initiative came around" (Group Director interview, 2016). Whilst they are asymmetrically structured and financed, this inductive analysis of the development, governance and function of the LIPs reveals six necessary conditions shared in common: anchorage, co-constitution, contextsensitivity, alignment, connection, shared functions (see Table 1).

LIPs are anchored between universities and the public sector although this takes different forms and has varying consequences. All participants provide meaningful commitment through finances, resources, time in-kind or space. Depending on context and need, these inter- actions included public agencies, research institutions, private actors and civil society representatives in varying degrees. Relationships with universities are present in all cases, but the extent of anchorage in research environments affords different risks and benefits in terms of institutional embeddedness, but also entanglements with already privileged spaces of knowledge production. For both CTLIP and GMLIP the source, flows and expectations of the funding model resulted in a greater reliance on University cash and in-kind match funding, which in turn led to a process of institutional enmeshing of LIP processes and structures into the respective research centres of ACC and SURF. Private sector partners have tended to play ancillary roles to the public sector.

LIPs are co-constituted and evolve organically with and in response to their local context. For example, in both Kisumu and Greater Manchester, the timing of the Centre's development coincided with periods of political change. This shifted policy priorities, for instance, through processes of devolution and structural change. Geography and size also played their part; in practice, there were different partnership arrangements and levels of complexity in working at different scales. Some LIPS focused on the urban-rural region (Kisumu, population 440,000 ), some on the city-county-region (Gothenburg, population 1.6 million and Greater Manchester population 2.7 million) and some on a single local authority in the context of pan-African links (Cape Town, population 3.7 million).

LIPs are context-sensitive and seek not only to produce excellent but also relevant knowledge (May \& Perry, 2016b) through building legitimacy, salience and credibility locally and constructing networks of different actors to address sustainability challenges. "Sustainable urbanisation" provided a springboard for all partnerships and the primacy of impact and relevance from funded projects and programmes motivated all the LIPs. However, there were variable articulations of what this meant in practice. The post-apartheid and post-colonial legacies were dominant tropes for Cape Town and Kisumu, shaping platform design and project evolution in terms of alignment with development agendas, economic growth (Kisumu) or the transformation agenda (Cape Town).

Table 1. Necessary conditions for LIPs.

\begin{tabular}{ll}
\hline Anchorage & Meaningful commitment from higher education and public sector partners \\
\hline Co-constitution & $\begin{array}{l}\text { Flexible and adaptive partnership structures which evolve over time according to geographic, } \\
\text { administrative and political factors }\end{array}$ \\
\hline Context-sensitivity & Research and practice agendas which reflect local sustainability issues and challenges \\
\hline Alignment & $\begin{array}{l}\text { An ability to align and embed local sustainability challenges within multi-scalar frameworks, } \\
\text { including at metropolitan, national and international levels }\end{array}$ \\
\hline Connection & $\begin{array}{l}\text { Common projects and processes which enable cross-LIP learning and support the transition } \\
\text { from particular to generalizable theories and practices }\end{array}$ \\
\hline Shared Function & The creation of boundary and interstitial spaces for interactions between sectors and disciplines \\
\hline
\end{tabular}


In the post-industrialising contexts of Gothenburg and Greater Manchester, city and regional initiatives had focussed on the development of innovation ecosystems and university-industry-government partnerships. As noted above, despite an initial expectation that the GOLIP approach would be rolled out as a common blueprint for the LIPs, delicate and sensitive adaptions to local contexts were necessary to gain legitimacy.

Local sustainability challenges are commonly aligned at multiple scales, through articulating between local issues and national and global sustainable development agendas. One example is the development of work within the Cape Town LIP within a pan-African context, related to SIDA's poverty reduction aspirations. The nesting of local within comparative projects, supported by the framework of the Urban SDG project, enabled the relationship between embedded local and internationally comparative work to be balanced. Such mechanisms also provide ways to ensure LIPs are connected to each other through common projects and comparative learning processes. This connection is essential in enabling knowledge developed locally to move from the particular to the general through the development of comparative insights, practices and theories.

Finally, the platform concept also has a shared function and value in practice as a jointly constituted space. LIPs provide a meeting arena where local, regional and state representatives can interact with academic researchers, outside their home-organisation restrictions. LIPs have been variably described as a "space and an opportunity for these stakeholders to come and share ideas, knowledge, challenges, experiences and even solutions that can drive sustainable urban development", as a "space in which we allow this to happen, outside of the ordinary processes that go on within each partner" (Group Director interviews, 2016). To this extent, following Ansell and Gash (2007), the institutional design of Mistra Urban Futures does not replace ordinary governmental agencies, but provides complementarity via the provision of spaces in-between of, or interdependent on, these agencies.

\subsection{Discussion}

The Mistra Urban Futures' LIPs are examples where "collaborative governance has emerged as a response to the failures of downstream implementation and the high cost of politicization of regulation" (Ansell \& Gash, 2007, p. 544). Participating partners at each platform work towards problem definitions, shared understandings, mutual trust, recognition of diversities, and a common learning process that can translate into practical benefits. In the struggle to govern the commons, Dietz, Ostrom and Stern (2003) note that ideal conditions are rare and stable institutional arrangements are unsuited to dealing with rapid change. Governing in complex systems requires three strategies: analytic deliberation, nesting and institutional variety. We argue that the LIP model is a dis- tinctive response to these issues working with and between "dialogue among interested parties, officials, and scientists; complex, redundant, and layered institutions; a mix of institutional types; and designs that facilitate experimentation, learning, and change" (Dietz et al., 2003, p. 1907). To this extent, the LIPs are co-productive boundary spaces, in the spirit of experimentalism. The value of this organizational form is two-fold: first, in privileging the creation of different spaces for interaction through which diverse processes and project types can evolve; second, in moving from a dualistic framing of the global and the local towards one that emphasizes hybridity and inter-relationality.

A common challenge faced by co-productive partnerships relates to the contradictory logics of bounding and enclosing urban space and contextualisation. To meet demands for accountability and certainty in complex multi-stakeholder partnerships, formal partnerships and processes are adopted. These often mirror fixed organisational structures, where tightly regulated decision spaces, geared towards consensus, replicate traditional decision-making fora. For certain urban experiments, controlling the environment is central to define the limits of what is in and out, and regulate spaces of knowledge production through processes that simultaneously open and close themselves to the possibilities of blending different forms of expertise and knowledge (Voß \& Bornemann, 2011). The risk is that, whilst recognising the importance of the need for context sensitivity, collaborative partnerships and experiments may reduce flexibility and responsiveness, seeking to fix the urban condition by getting the right people around the table or isolating specific variables and issues.

At the same time there are tensions in how the logic of contextualisation manifests in practice. The urban context is simultaneously valued and devalued. It is recognised as constituting the conditions in which experiments unfold, and as central in shaping and defining specific problem spaces. Context matters, but should not overdetermine or ignore the multi-scalar interconnections and embeddedness of the city within wider systems of production and exchange. Local contextualisation may run the risk of global disconnection, as if cities were bounded objects out of time and space. Lawhon and Patel (2013) caution that a consequence of the devolution to the local and its resulting dislocation is the occlusion of questions of global responsibility and justice. The experimental and contextual turn cannot isolate from multiscale and interconnected space and need for generalizable as well as particular knowledge. On the other hand, cities are also positioned as little more than testbeds for experiments that can be rolled out to other contexts following the traditional "best practice" approach (Patel et al., 2015). Here the global transcends the local in the search for governance fixes to complex sustainability challenges.

LIPs are one response to these challenges, innovations in the social organisation of knowledge (May \& 
Perry, 2016b). The experience of the LIPs suggests that platforms are ways of organising that allow for diversity and plurality in relationships, offer different kinds of spaces, defined variably as "safe", "unaligned", "neutral" or "deliberative". They provide interstitial mechanisms for social learning across and with partners, bridging the local and the global. Context-sensitivity and iterative flexibility enable platforms to articulate between internationally shared priorities and distinctive local practices. Further, we have argued that the necessary conditions for the formation of the LIP are: anchorage, co-constitution, context-sensitivity, alignment, connection and shared functions. Their value is in working with, rather than seeking to protect from, the uncertainty and complexity of urban governance, moving beyond the single bounded experiment towards international connectedness.

\section{Unbounding Experimentalism}

Co-production is a response to procedural and epistemic deficiencies. This includes, on the one hand, recognition that existing forms of urban governance and elite decision-making processes are insufficient to address contemporary multiple-problem challenges and, on the other, that implementable solutions in practice cannot develop without drawing on distributed forms of expertise beyond the usual technocratic fix. These epistemic and procedural deficits have given rise to a wave of new governance arrangements, urban experiments and place-based initiatives in efforts to redesign structures and processes for addressing intractable urban challenges. This article contributes to re-imagining how urban governance can be more fit-for-purpose through opening such new interstitial spaces for social innovation and learning within co-productive boundary space.

LIPs are one response to developing fit-for-purpose partnership forms for addressing wicked issues and epistemic messes. They have wider relevance in contributing to urban governance debates for two reasons, as outlined above. First, it is increasingly recognised that cities require adaptive governance and new forms of leadership and partnerships for cross-sector working. In a context where the challenge is to respond urgently to multiple crises, flexibility and responsiveness are key attributes of successful governance arrangements. The early experience of the LIPs suggests they offer a flexible and adaptive organisational form which fosters coproductive processes in rapidly changing and complex urban governance environments. Second, whilst there has been a much-needed turn to context-specificity and locally-relevant work, this has been accompanied by equal concern about the fetishization of the local and dangers of the "local trap" (Purcell, 2006). Through their evolution, LIPs are seeking to balance between global and local pressures in the search for both global relevance and sensitivity to context.

Three further areas for study and practice emerge. First, it is important to understand more about the dynamics of boundary work in practice. Whilst much of the literature has contributed to evaluating concepts and models of new boundary organisations, there has been less focus on the mechanisms and tools for building capacity and the practices of linking between knowledge and action. This means that practical guidance on how to govern adaptively is under-developed (Wyborn, 2015). Second, the politics of co-production needs greater attention (Flinders, Wood, \& Cunningham, 2016). There has been insufficient critical examination of the presumed "neutrality" or "safeness" of new boundary spaces. Language used to describe the nature of these spaces varies widely across cities and partners. Patterns of inclusion and exclusion, political orientations and processes of inclusion and exclusion are hidden but palpable. For the LIPs both issues are ongoing concerns. In 2015, following the successful mid-term evaluation, a further four years' funding was allocated. Having built "co-productive capacities" on the ground (Wyborn, 2015), the next step is to support reflexive analysis and double-loop learning processes which illuminate the practices and politics of participation across the platforms. A further challenge is to build on the distinctive make-up of the Centre to contribute to both methodological and substantive debates on how to realise more just cities. This requires innovative project designs which rethink the processes and practices of co-productive and comparative urban research.

\section{Acknowledgements}

We acknowledge funding from the Mistra Strategic Environmental Research Foundation for its support to the Mistra Urban Futures Centre and co-funders of local platforms. Zarina Patel acknowledges funding from the National Research Foundation Incentive Fund. We remain responsible for the arguments in this article. We would like to acknowledge the following participants in the research: David Simon, Stephen Agong and Warren Smit. Finally, we would like to acknowledge all those involved in the Centre and our respective platforms for conceptualizing and operationalizing the work.

\section{Conflict of Interests}

The authors declare no conflict of interests.

\section{References}

Ackoff, R. L. (1979). The future of operational research is past. Journal of the Operational Research Society, 30(2), 93-104.

Ansell, C., \& Gash, A. (2007). Collaborative governance in theory and practice. Journal of Public Administration Research and Theory, 18(4), 543-571.

Argyris, M., \& Schön, D. (1974). Theory in practice. Increasing professional effectiveness. San Francisco, CA: Jossey-Bass. 
Beck, U. (1992). Risk society: Towards a new modernity. London: Sage.

Bulkeley, H., \& Betsill, M. M. (2005). Cities and climate change: Urban sustainability and global environmental governance. Hove: Psychology Press.

Bulkeley, H., \& Castán Broto, V. (2013). Government by experiment? Global cities and the governing of climate change. Transactions of the Institute of British Geographers, 38, 361-375.

Davison, A., Patel, Z., \& Greyling, S. (2016). Tackling wicked problems and tricky transitions: Change and continuity in Cape Town's environmental policy landscape. Local Environment, 21(9), 1063-1081.

Dietz, T., Ostrom, E., \& Stern, P. (2003). The struggle to govern the commons. Science, 302(5652), 1907-1912.

Durose, C., \& Richardson, L. (2015). Designing public policy through co-production: Theory, practice and change. Bristol: Policy Press.

Evans, J. (2016). Trials and tribulations: Problematizing the city through/as urban experimentation. Geography Compass, 10(10), 429-443.

Flinders, M., Wood, M., \& Cunningham, M. (2016). The politics of co-production: Risks, limits and pollution. Evidence and Policy, 12(2), 261-279.

Geertz, C. (1973). The interpretation of cultures. New York, NY: Basic Books Classics.

Glasbergen, P., Biermann, F., \& Mol, A. P. J. (Eds.). (2007). Partnerships, governance and sustainable development: Reflections on theory and practice. Cheltenham: Edward Elgar Publishing Ltd.

Grin, J., Rotmans, J., \& Schot, J. (2010). Transitions to sustainable development. London: Routledge.

Head, B. J., \& Alford, J. (2015). Wicked problems: Implications for public policy and management. Administration \& Society, 47(6), 711-739.

Kain, J. H., Nolmark, H., Polk, M., \& Reuterswärd, L. (2011). Strategic plan: 2012-2015. Cape Town, Gothenburg, Sheffield, Manchester, Kisumu, Skåne, and Stockholm: Mistra Urban Futures.

Kernaghan, K. (1993). Partnerships and public administration: Conceptual and practical considerations. Canadian Public Administration, 36, 57-76.

Lang, D. J., Wiek, A., Bergmann, M., Stauffacher, M., Martens, P., Moll, P., \& Thomas, C. J. (2012). Transdisciplinary research in sustainability science: Practice, principles and challenges. Sustainability Science, 7(Supplement 1), 25-43.

Lawhon, M., \& Patel, Z. (2013). Scalar politics and local sustainability: Rethinking governance and justice in an era of political and environmental change. Environment and Planning C, 31(6), 1048-1062.

Marvin, S., \& May, T. (2017). The future of sustainable cities: Governance, policy and knowledge. Local Environment, 22, 1-7.

May, T., \& Perry, B. (2016a). Cities, experiments and the logics of the knowledge economy? In J. Evans, A. Karvonen, \& R. Raven (Eds.), The experimental city (pp. 32-47). London: Routledge.
May, T., \& Perry, B. (2016b). Knowledge for just urban sustainability. Local Environment, 22(Supplement 1), 23-35. doi:10.1080/13549839.2016.1233527

May, T., \& Perry, B. (2017a). Reflexivity. The essential guide. London: Sage.

May, T., \& Perry, B. (2017b). Cities and the knowledge economy: Promise, politics and possibilities. Oxford: Routledge.

Mistra. (2008). Urban futures-Call for pre-proposals. Cape Town, Gothenburg, Sheffield, Manchester, Kisumu, Skåne, and Stockholm: Mistra Urban Futures.

Mistra Urban Futures. (2015). Progress report 20102014. Retrieved from https://www.mistraurban futures.org/sites/mistraurbanfutures.org/files/mistra urbanfutures-progressreport-digital.pdf

Moser, P. (2013). Integrating urban knowledge. In H. T. Anderson \& R. Atkinson (Eds.), Production and use of urban knowledge (pp. 17-34). Netherlands: Springer.

Norén Bretzer, Y. (2016). How to organise for change: Local practice vs global transitions. In $\mathrm{H}$. Palmer \& $\mathrm{H}$. Walasek (Eds.), Co-production in action: Towards realising just cities (pp. 22-31). Gothenburg: Mistra Urban Futures.

Nowotny, H., Scott, P., \& Gibbons, M. (2001). Re-thinking science: Knowledge and the public in an age of uncertainty. Cambridge: Polity.

Ostrom, E. (1990). Governing the commons: The evolution of institutions of collective action. Cambridge: Cambridge University Press.

Palmer, H., \& Walasek, H. (2016). Co-production in action: Towards realising just cities. Gothenburg: Mistra Urban Futures.

Patel, Z., Greyling, S., Parnell, S., \& Pirie, G. (2015). Coproducing urban knowledge: Experimenting with alternatives to 'best practice' for Cape Town, South Africa. International Development Planning Review, 37(2), 187-203.

Pelling, M., High, C., Dearing, J., \& Smith, D. (2008). Shadow spaces for social learning: A relational understanding of adaptive capacity to climate change within organisations. Environment and Planning $A$, 40, 867-884.

Perry, B., \& Atherton, M. (2017). Beyond critique: The value of co-production in realising just cities? Local Environment, 22(Supplement 1), 36-51. doi:10.1080/13549839.2017.1297389

Pohl, C., Rist, S., Zimmermann, A., Fry, P., Gurung, G. S., Schneider, F., . . W Wiesmann, U. (2010). Researchers roles in knowledge co-production: Experience from sustainability research in Kenya, Switzerland, Bolivia and Nepal. Science and Public Policy, 37(4), 267-281.

Polk, M. (Ed.). (2015). Co-producing knowledge for sustainable cities: Joining forces for change. Abingdon: Routledge.

Polk, M., Malbert, B., \& Kain, J. H. (2009). Mistra Urban Futures: The Göteborg Center of Excellence for Sustainable Urban Futures. Gothenburg: Mistra Urban Futures. 
Purcell, M. (2006). Urban democracy and the local trap. Urban Studies, 43(11), 1921-194.

Rittel, H. W. J., \& Webber, M. M. (1973). Dilemmas in a general theory of planning. Policy Sciences, 4(2), 155-169.

Shami, S. (2003). Ethnographies of governance: Urban spaces and actors in the Middle East. In P. L. McCarney \& R. E. Stren (Eds.), Governance on the ground: Innovations and discontinuities in cities of the developing world (pp. 56-82). Baltimore, MD: John Hopkins Press.

Simon, D., Arfvidsson, H., Anand, G., Bazaz, A., Fenna, G., Foster, K., . . . Wright, C. (2015). Developing and testing the urban sustainable development goals targets and indicators-A five-city study. Environment and Urbanization, 28(1), 1-15. doi:10.1177/0956247815619865
Trencher, G., Bai, X., Evans, J., McCormick, K., \& Yarime, M. (2014). University partnerships for co-designing and co-producing urban sustainability. Global Environmental Change, 28, 153-165. doi:10.1016/j.gloenvcha.2014.06.009

United Nations Habitat III Conference. (2016, May). Zero draft of the new urban agenda. New York, NY: United Nations.

Voß, J. P., \& Bornemann, B. (2011). The politics of reflexive governance: Challenges for designing adaptive management and transition management. Ecology and Society, 16(2), 9-32.

Wyborn, C. (2015). Connecting knowledge with action through co-productive capacities: Adaptive governance and connectivity conservation. Ecology and Society, 20(1). doi:10.5751/ES-06510-200111

\section{About the Authors}
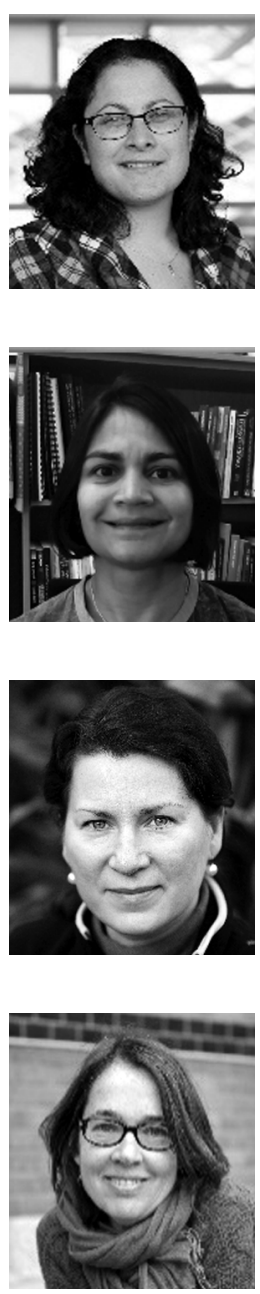

Beth Perry is a Professorial Fellow at the Urban Institute and Urban Studies and Planning, University of Sheffield. Her work focusses on coproduction, urban governance and the just city. She has recently co-authored two books with Tim May on Reflexivity: An Essential Guide (Sage) and Cities and the Knowledge Economy: Promise, Politics and Possibility (Routledge). She is leading a multi-million programme of work (2016-2019) on Realising Just Cities with funding from Mistra Urban Futures and the Economic and Social Research Council.

Zarina Patel is a senior lecturer in the Environmental and Geographical Sciences at the University of Cape Town. Zarina's research is concerned with the multiple dimensions of the meanings and practice of sustainable development at the city scale. She serves on the editorial board of Local Environment: The International Journal of Justice and Sustainability, and is the newly appointed editor of Urban Forum.

Ylva Noren Bretzer works at the Department of Public Administration at the University of Gothenburg. Her academic contributions include works on citizen trust in public agencies, implementation of energy efficiency in residential areas and social sustainable development in deprived neighborhoods. She is specifically interested in evaluations of the implementation aspects of various policies, and how these turn out in relation to citizens and civil society.

Merritt Polk is a Professor in Human Ecology at the School of Global Studies, University of Gothenburg. Her most recent research is on different methods and approaches for transdisciplinary co-production. She focuses on what learning entails in transdisciplinary approaches and how the relationship between co-production processes and contributions to societal impact can be attributed and evaluated. 